\title{
ESTUDO DAS CAUSAS DE PROJEÇÕES DE ESCÓRIA NO CONVERTEDOR LD*
}

Camila Barbosa Albani ${ }^{1}$

Henrique Silva Furtado ${ }^{2}$

José Roberto de Oliveira ${ }^{3}$

\section{Resumo}

Foram estudados os tipos de projeções, suas características e medidas de controle, a partir do acompanhamento de corridas na ArcelorMittal Tubarão, inclusive com amostragem e análises dos resíduos de projeção. Utilizando-se termodinâmica computacional estimou-se a viscosidade da projeção, que se mostrou muito heterogênea. Projeções ocorreram em uma faixa extensa de Si do gusa, inclusive em valores abaixo de 0,30\%, com maior frequência entre $0,30 \%$ e $0,40 \%$. As adições de minério de ferro tiveram forte influência na ocorrência de projeções possivelmente devido ao efeito conjugado de redução da permeabilidade e geração de gás. Um modelo conceitual das causas principais das projeções foi proposto e validado com observações de ocorrência de projeções tardias no sopro. Foi também proposto que as ações de controle de projeções deveriam ser ajustadas de forma a priorizar o controle da taxa de descarburação e o aumento da permeabilidade da emulsão.

Palavras-chave: Controle de projeções; Projeção; Refino primário; Convertedor LD.

\section{STUDY OF SLAG SLOPPING CAUSES IN A LD CONVERTER}

\begin{abstract}
Different types of slopping were studied, their characteristics and control measures. Concerning this research, heats were observed at ArcelorMittal Tubarão also some samples were taken to chemical analysis. Viscosities were predicted based on their chemistry using thermodynamic simulation that evidenced a large heterogeneity. Slopping occurred in all hot metal Si spectrum including values lower than $0.3 \%$ with more frequency of heat with content in a range of $0.3 \%$ to $0.4 \%$. Iron ore addition as coolant played an important role in slopping occurrence probably due to its effect on increase foam viscosity and gas generation. A conceptual model is proposed and validated using arguments based on closer to the end of blow slopping occurrence. The conclusion for control action is that some should prioritize decarburization rate and foam permeability.
\end{abstract}

Keywords: Slopping control; Slopping; Primary steelmaking; LD converter.

1 Graduanda em Engenharia Metalúrgica. Instituto Federal do Espírito Santo, Vitória, ES, Brasil

2 Engenheiro Metalúrgico, PhD, Especialista de Pesquisa e Desenvolvimento do centro de pesquisa da ArcelorMittal para a América do Sul. Vitória, ES, Brasil.

3 Prof. Dr. do Instituto Federal do Espírito Santo, dos cursos de graduação e pós-graduação em Engenharia Metalúrgica e de Materiais. Vitória, ES, Brasil. 


\section{INTRODUÇÃO}

Durante o processo de conversão do gusa por injeção de oxigênio (processos tipo LD) ocorre a formação de uma emulsão gás-metal-escória, que é de fundamental importância para as reações de refino e é a grande responsável pela elevada produtividade destes reatores. Entretanto, se esta emulsão for instável pode ocorrer o seu transbordamento para fora do convertedor LD, fenômeno esse chamado de projeção, que pode acontecer em diferentes momentos do sopro, apresentando características espumosa, reativa ou explosiva.

Compreender o fenômeno da projeção e de que maneiras ele pode ser evitado ou controlado é estratégico para a indústria siderúrgica. As perdas metálicas causadas por esse fenômeno estão entre 10 e $20 \%$ do banho metálico [1]. Além disso, existem perdas em formas de fumos, causadas pela má formação de escória, que podem chegar a $25-30 \mathrm{~kg} / \mathrm{t}$ de aço [2]. Os gases e fuligem gerados podem levar a poluição atmosférica, visto que o sistema de captação e limpeza dos gases pode não suportar a súbita elevação de vazão que ocorre no momento da projeção.

Modelos desenvolvidos a partir de ensaios laboratoriais têm sido utilizados para avaliar a propensão de um sistema para emulsificação. Estudos de Cicutti et al [3] mostram que a presença de partículas não dissolvidas na escória aumenta o índice de emulsibilidade em decorrência do aumento da viscosidade; e também que a altura da emulsão é máxima próximo de $35 \%$ do sopro.

Uma vez caracterizado o instante em que ocorrem as projeções, é preciso compreender quais as causas que levam ao fenômeno, e qual a melhor maneira de controlá-lo antes de acontecer, bem como durante. Assim, o presente artigo tem por objetivo discutir alguns mecanismos ativadores da projeção, assim como avaliar criticamente ações utilizadas com frequência, objetivando o seu controle.

\section{MATERIAIS E MÉTODOS}

O trabalho experimental foi desenvolvido utilizando o método científico, de maneira que as etapas envolvidas no processo foram: observação do fenômeno projeção de escória nos convertedores; coleta de amostras de escória de projeção; análise química e cálculo de viscosidade das escórias; elaboração de modelo conceitual; validação do modelo conceitual.

No período de 25 de julho de 2016 a 30 de setembro de 2016 foram acompanhadas 100 corridas nos convertedores da aciaria da ArcelorMittal Tubarão. Dessas corridas, 44 apresentaram alguma forma de projeção. Durante este período foram registradas as características de cada corrida, como padrão de sopro, porcentagem de Si no ferro gusa líquido, se houve projeção e em que momento, qual a classificação da projeção e como ela foi controlada, qual a aparência da escória e se a projeção ocorreu após a adição de fundentes e/ou refrigerantes. Além desses dados, foram registradas as observações e sugestões da operação, bem como qualquer anormalidade presente no dia, assim como imagens das projeções, com uma câmera fotográfica digital.

Para melhor compreender as características da escória de projeção, criou-se um dispositivo para coleta de amostras de escória de projeção. O dispositivo foi 
posicionado próximo à região do furo de corrida, onde foi possível coletar amostras de projeções reativas. Foram coletadas amostras de 7 corridas. A Figura 1 ilustra 0 dispositivo fabricado.

As amostras de projeção coletadas no acompanhamento pelo dispositivo foram analisadas quimicamente no laboratório da ArcelorMittal Tubarão, por meio de fluorescência de raios-x, enquanto a parte metálica foi analisada por espectroscopia óptica. A partir da análise quantitativa dos elementos presentes nas amostras estimou-se a viscosidade das escórias no momento da projeção, propriedade importante para análise da emulsificação. Esta estimação foi feita utilizando-se o software CEQSCI® (Chemical Equilibrium Calculation for the Steel Industry), que é um programa de cálculo de equilíbrio multifásico desenvolvido pelo grupo ArcelorMittal. Nesse caso, utilizou-se o módulo Cristal, versão 16.02, que simula a viscosidade das fases da escória, para uma escória líquida e para uma mistura sólido-liquido. Este módulo calcula a viscosidade utilizando diferentes modelos, simultaneamente. Neste estudo utilizou-se o modelo Urbain_h, pois este leva em consideração as fases sólidas presentes. Além disso, o modelo Urbain é o indicado para escórias de aciaria, uma vez que considera na simulação os teores de $\mathrm{SiO}_{2}$, $\mathrm{P}_{2} \mathrm{O}_{5}, \mathrm{TiO}_{2}, \mathrm{Cr}_{2} \mathrm{O}_{3}, \mathrm{Al}_{2} \mathrm{O}_{3}, \mathrm{FeO}_{\mathrm{t}}, \mathrm{MnO}, \mathrm{MgO}, \mathrm{CaO}, \mathrm{K}_{2} \mathrm{O}, \mathrm{Na}_{2} \mathrm{O}, \mathrm{CaF}_{2}$. O intervalo de temperatura usado foi de $1200^{\circ} \mathrm{C}$ a $1750^{\circ} \mathrm{C}$, e a variação para obtenção dos dados foi de $5^{\circ} \mathrm{C}$. A pressão utilizada foi $1 \mathrm{~atm}$.

Nesta fase, procurou-se formular um modelo conceitual que visa explicar a dinâmica da projeção nos convertedores da ArcelorMittal Tubarão usando como inspiração os conhecimentos consolidados na literatura corrente, assim como opiniões dos operadores e observações do próprio autor coletadas na primeira fase. A validação ou o falseamento das hipóteses foi realizado através de parte dos dados coletados. Por fim, sumarizou-se as conclusões sobre as causas das projeções, assim como as recomendações para atenuá-las.

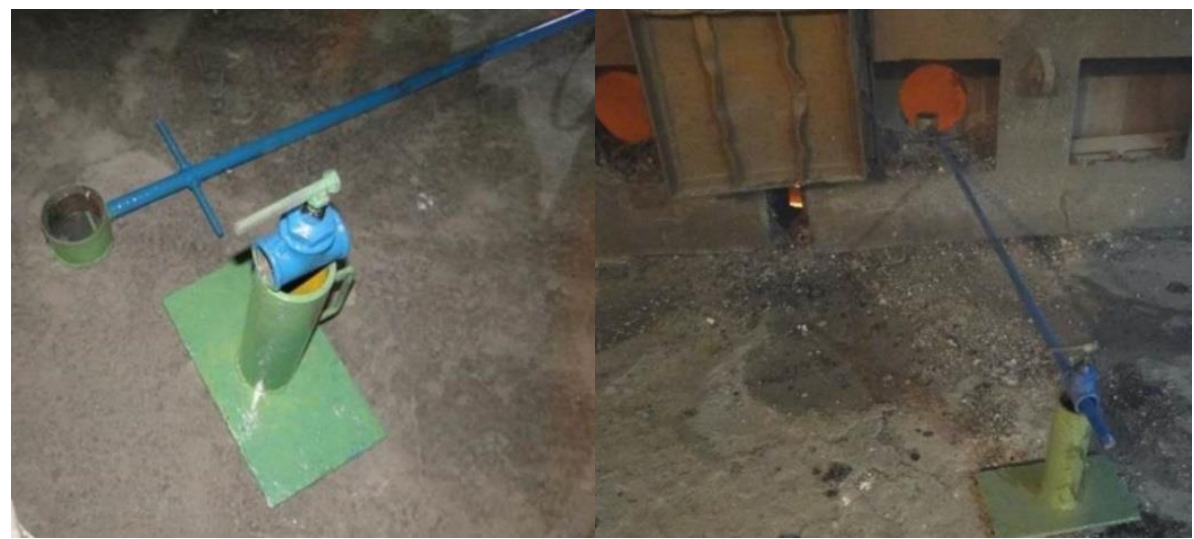

Figura 1. Dispositivo de coleta de amostra de escória. Fonte: Elab. pelo autor, 2016.

\section{RESULTADOS E DISCUSSÃO}

Foram observados dois tipos de projeção, classificados como projeção espumosa e projeção reativa, e que estão representados na Figura 2. As projeções espumosas aconteceram nos primeiros momentos do sopro, entre três e cinco minutos ( $20 \%$ do sopro). O material que transbordava na boca do convertedor apresentou aparência 
viscosa, a projeção não era violenta e de mais fácil controle. Além disso, a escória apresentava claramente fluxantes não dissolvidos. As projeções reativas aconteciam predominantemente entre sete e 10 minutos de sopro (50 a $60 \%$ do sopro). As projeções eram mais violentas, com ondas de escória fluida e de difícil controle, evidenciado pela sua persistência após a interrupção do sopro.

Das 44 projeções observadas, $68 \%$ ocorreram antes dos 8 minutos de sopro, e $66 \%$ ocorreram durante ou após a adição de minério de ferro ou outro material refrigerante.

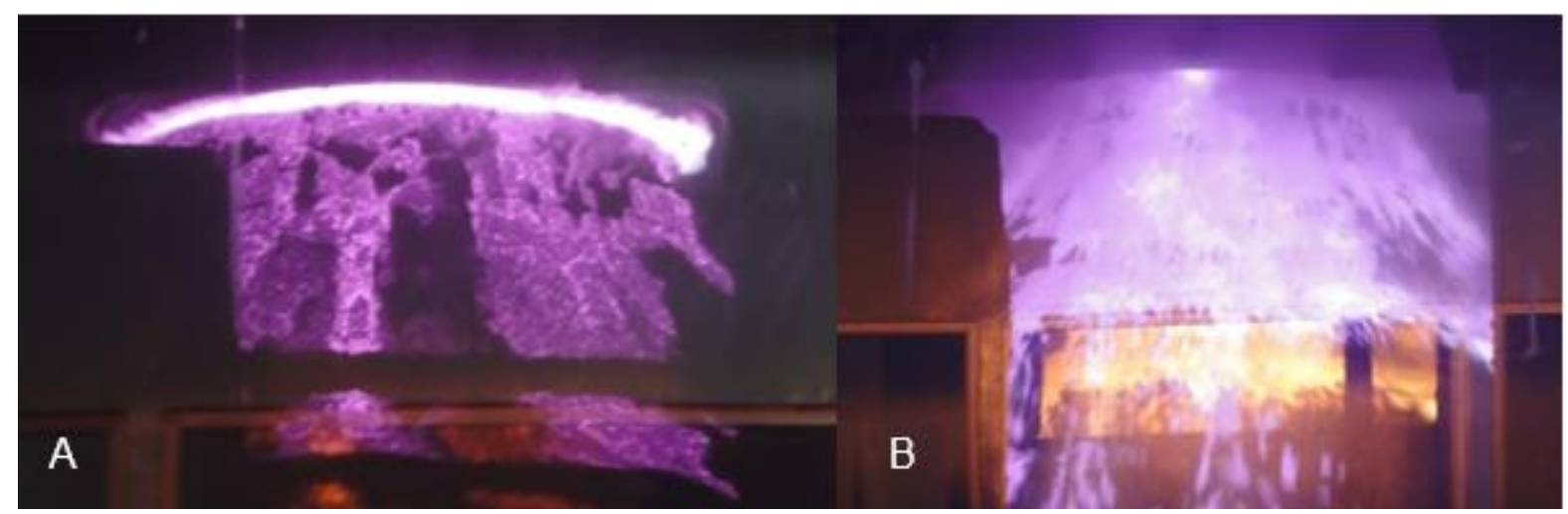

Figura 2. (A) Projeção espumosa e (B) Projeção reativa. Fonte: Elab. pelo autor, 2016

Os teores de silício nas corridas que apresentaram projeções foram resumidos na Figura 3. De maneira geral, observa-se que as projeções ocorreram em uma ampla faixa de $\mathrm{Si}$ do gusa. De fato, mais da metade das projeções $(68,8 \%)$ ocorreram quando o teor de Si estava entre 0,30 e 0,49\%. Esse teor de Si não é considerado alto para os padrões de operação.

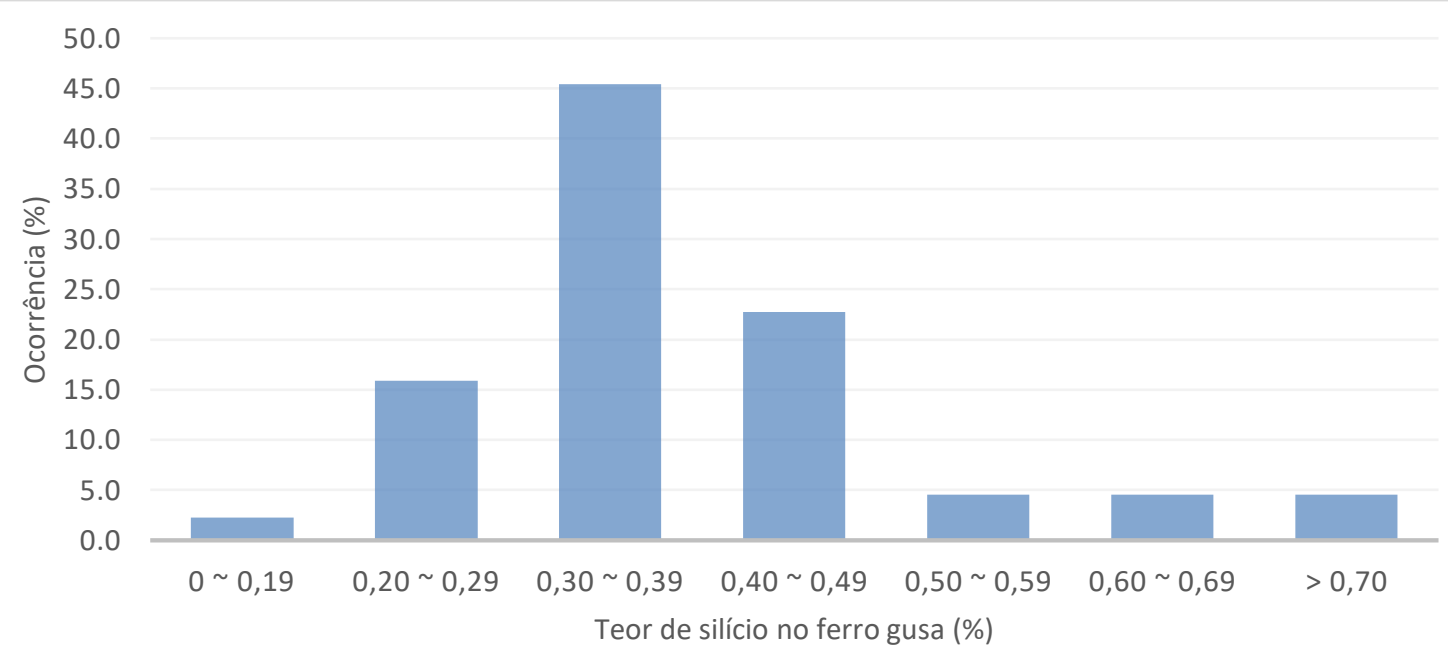

Figura 3. Teor de silício no ferro gusa em corridas que apresentaram projeção. Fonte: Elab. pelo autor, 2016.

O volume de escória é controlado pelo teor de Si do gusa, pelas adições e pela oxidação do ferro. Para teores de Si baixo, a especificação de $\mathrm{P}$ de final de sopro e a proteção da lança e refratário demandam a adição de fontes de Si para produzir um volume mínimo. Neste caso, o balanço térmico fica mais desfavorável (menor aporte e mais gasto para escorificação dos materiais). Neste contexto, pode-se 
especular que as projeções poderiam ter ocorrido pela redução significativa da temperatura nos momentos iniciais do sopro, com consequente aumento da viscosidade e redução da permeabilidade dos gases. Por outro lado, teores de Si elevados impõem um elevado volume de escória e um acentuado aporte térmico, que nos casos em questão foram compensados por elevadas adições de minério.

Como mencionado anteriormente, uma elevada fração das corridas com projeções apresentava adições significativas de refrigerante (minério ou briquete). Na Figura 4 observa-se uma tendência de aumento da frequência de projeção com o aumento da adição de refrigerante. Uma interrupção desta tendência é observada entre as faixas "6,0-7,9" e "8,0-9,9" provavelmente devido à prática de fracionamento das adições.

Este comportamento pode ser explicado pelo fato do minério de ferro apresentar um elevado poder de refrigeração, e ao se decompor aumenta a disponibilidade de oxigênio para a reação de descarburação. A consequência é um aumento da viscosidade da escória, diminuindo a sua permeabilidade a saída dos gases, e simultaneamente um aumento da geração desses gases.

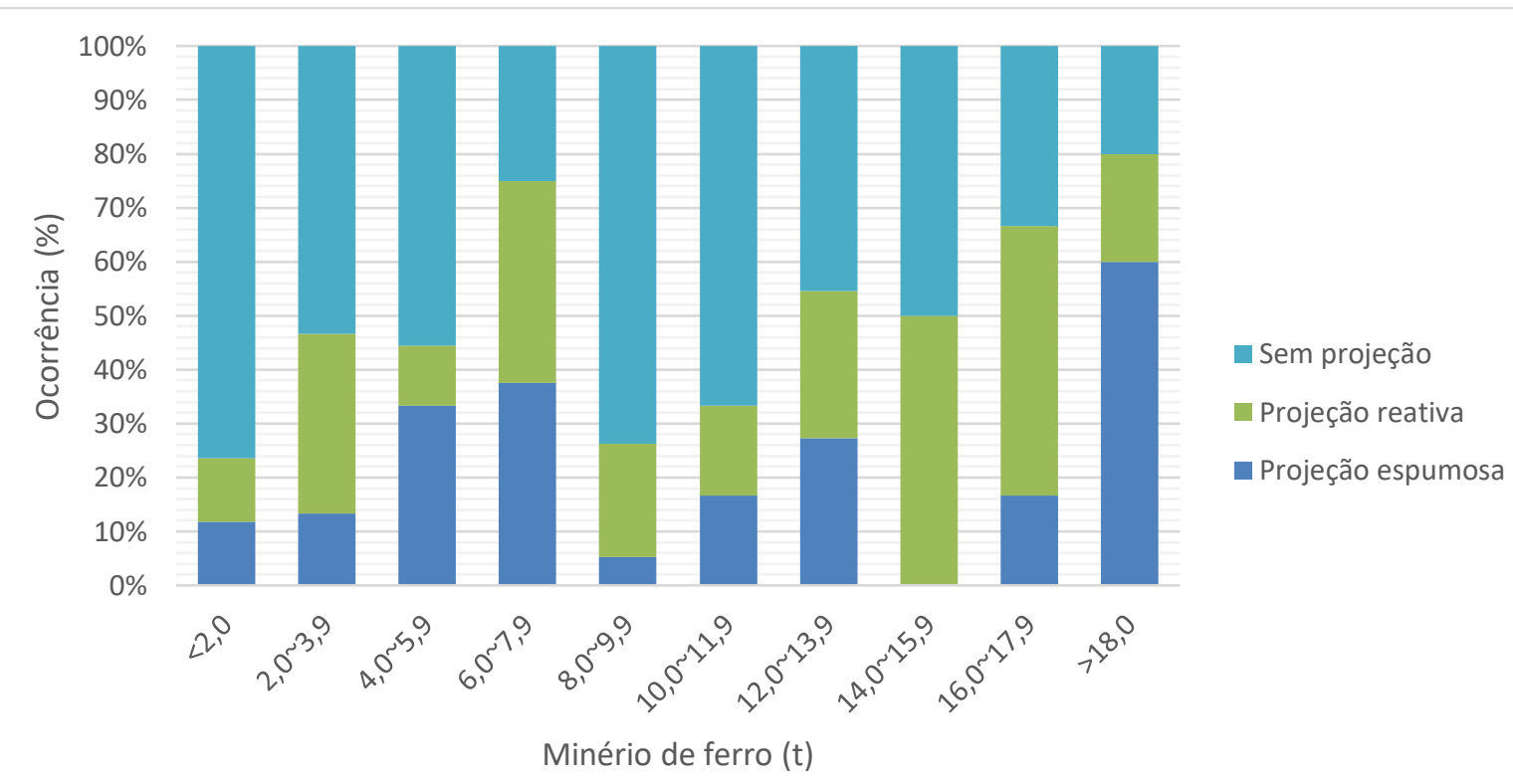

Figura 4. Comparação entre as adições de minério de ferro em corridas com e sem projeção. Fonte: Elab. pelo autor, 2016.

Os padrões de sopro afetam fundamentalmente a oxidação do ferro e a descarburação e, portanto, a formação da emulsão. Estes são codificados na ArcelorMittal Tubarão com um número que indica a intensidade de agitação do banho, de acordo com a Tabela 1.

Pela análise da Tabela 1, observa-se que nas corridas onde houve projeção uma tendência quase que linear de menor utilização de padrões mais macio com uma concentração em padrões mais duros. Por outro lado, nas corridas sem projeção, a escolha do tipo de padrão a ser usado parece mais equilibrada. Isto decorre do fato do padrão ser definido automaticamente em função do teor de Si do gusa e do peso de minério de ferro recomendado para o sopro. 
Tabela 1. Padrões de sopro

\begin{tabular}{lcc}
\hline & Corridas com projeção (\%) & Corridas sem projeção (\%) \\
\hline $\mathbf{2 - 3}$ (mais macio) & 4,5 & 25,0 \\
\hline $\mathbf{4}$ & 9,1 & 20,5 \\
\hline $\mathbf{6}$ & 13,6 & 22,7 \\
$\mathbf{6}$ & 20,5 & 36,4 \\
\hline $\mathbf{7 - 8}$ (mais duro) & 52,3 & 15,9 \\
\hline
\end{tabular}

Fonte: Elab. pelo autor, 2016.

A lógica dos resultados da Tabela 1 estabelece que em situações de maiores volumes de escória e de adições substanciosas de minério deve-se acelerar as reações de refino de forma a gerar mais calor no sistema. Dessa forma, reduzir-se-ia o efeito do minério no aumento da viscosidade (redução da permeabilidade da escória), assim como o acumulo de oxigênio no convertedor, limitando assim a geração de gás pela descarburação no início do segundo período, onde a taxa desta reação é máxima.

Entretanto, uma baixa reatividade das cales associada a um baixo teor de $\mathrm{FeO}$ da escória pode manter a viscosidade da escória elevada, especialmente se frações elevadas de minério forem adicionadas ainda na primeira etapa de descarburação próxima do início da segunda.

Em resumo, o sopro duro num convertedor cheio de escória parece razoável desde que a emulsão tenha elevada permeabilidade. Caso contrário, deve-se atuar na redução da geração de gás, favorecida por vazões menores de oxigênio.

A análise laboratorial das amostras de projeção (8 amostras de escória de projeção, sendo duas da mesma corrida e as demais de corridas diferentes) obtidas com o dispositivo mostrado na Figura 1, foi usada para estimar a viscosidade por meio de termodinâmica computacional. Os dados da análise química são apresentados na Tabela 2. Curvas de viscosidade em função da temperatura para cada uma das análises são apresentadas na Figura 5.

A despeito de apresentarem resultados distintos de viscosidade em temperaturas mais baixas, todas estas corridas apresentaram teores de silício do gusa acima de 0,40\%; adições elevadas de refrigerantes (de 8 a 20 t de minério) e padrão de sopro de número 8 , o mais duro de todos. Esta variabilidade na viscosidade calculada pode estar associada ao carácter muito heterogêneo da projeção. Isto é forçado pelos resultados distintos de viscosidade da corrida 2-11832-3.

De fato, as projeções das corridas analisadas evoluíram de um caráter espumoso para reativo. Isto é um indicativo que sugere uma emulsão bastante heterogênea, onde na camada mais superficial estaria a uma temperatura menor e com uma quantidade significativa de materiais não dissolvidos, e uma mais interna com temperatura mais elevada e consequentemente mais fluida.

Tabela 2. Dados de análise química das amostras de escória

\begin{tabular}{ccccccccc}
\hline Corrida & Al2O3\% & CaO\% & CaOLA $\%$ & FeT\% & MgO $\%$ & MnO\% & P2O5\% & SiO2\% \\
\hline $\mathbf{1 1 5 0 6 2 7}$ & 1,89 & 33,4 & 3,41 & 26,6 & 9,87 & 7,69 & 1,88 & 16,2 \\
\hline $\mathbf{2 1 1 8 1 7 6}$ & 1,74 & 34,6 & 3,1 & 20,6 & 8,64 & 9,39 & 1,86 & 22,1 \\
\hline $\mathbf{2 1 1 8 2 7 7}$ & 1,26 & 42,6 & 8,72 & 24,1 & 9,78 & 4,4 & 0,9 & 9,8 \\
\hline $\mathbf{2 1 1 8 3 2 3}$ & 1,78 & 37,9 & 3,12 & 22,4 & 10,2 & 6,3 & 1,71 & 16,1 \\
\hline
\end{tabular}




\begin{tabular}{ccccccccc}
\hline $\mathbf{2 1 1 8 3 2 3}$ & 2,31 & 45,7 & 4,19 & 19,4 & 8,94 & 4,32 & 1,88 & 10,2 \\
\hline $\mathbf{1 5 0 8 3 0 0}$ & 1,5 & 45,4 & 6,65 & 14,2 & 12 & 4,84 & 1,44 & 15,4 \\
\hline $\mathbf{1 5 0 8 2 9 1}$ & 2,01 & 33,9 & 0,84 & 21,8 & 8,78 & 6,44 & 1,91 & 21,4 \\
\hline $\mathbf{1 5 0 8 2 9 9}$ & 1,99 & 42,3 & 4,06 & 14,6 & 9,9 & 5,86 & 2,03 & 19,9 \\
\hline
\end{tabular}

Fonte: Elab. pelo autor, 2016.

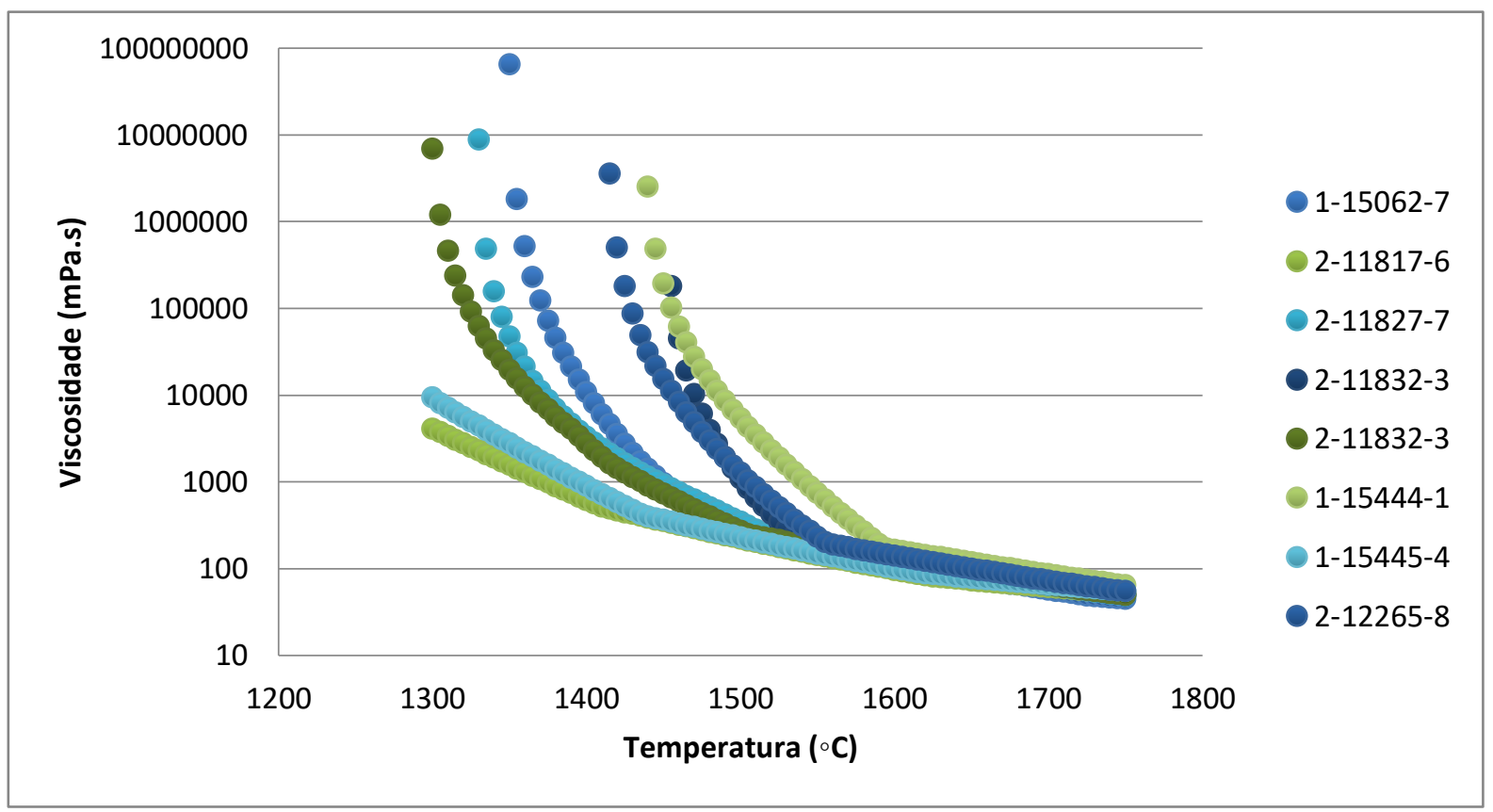

Figura 5. Viscosidade de amostras de escória de projeção das corridas indicadas ao lado. Fonte:

Elab. pelo autor, 2016

Durante o acompanhamento, notou-se o uso de diversas medidas de controle isoladamente ou em conjunto com diferentes graus de sucesso, que estão listadas no Quadro 1. Em geral, as fortes projeções reativas foram controladas somente com a interrupção do sopro, ou seja, com uma redução brusca da geração de gás. Não obstante, o controle das projeções do tipo espumosa era bem sucedido com medidas conjugadas de adição de dolomita crua, interrupção da adição de minério, redução da vazão de $\mathrm{O}_{2}$ e redução da altura de lança. $\mathrm{Na}$ essência estas medidas foram implementadas para reduzir a resistência à passagem dos gases (adição de dolomita crua gera uma abertura na emulsão) e reduzir a geração de gases com a redução da vazão de oxigênio, e não para minimizar um efeito colateral deste último no aumento do volume de escória. Este é decorrente do aumento do teor de ferro oxidado através redução da altura de lança.

Quadro 1. Medidas de controle usadas em projeções.

Elevação da saia do convertedor

Interrupção da adição de minério

Aumento da vazão de gás inerte pelo fundo do convertedor

Adição de dolomita crua

Redução da Vazão de $\mathrm{O}_{2}$

Redução da altura da distância lança-banho

Adição de cales

Interrupção do sopro

Remoção de parte da escória do forno

Fonte: Elab. pelo autor, 2016. 
O sucesso no controle da projeção no convertedor depende fortemente do momento do sopro. De fato, uma medida de controle que pode resultar em sucesso quando a projeção está desenvolvida, como a adição de dolomita crua, pode se configurar em um desastre quando a emulsão ainda está se formando. Se for tomada outra medida para secar a escória, pode-se gerar uma descarburação explosiva. Portanto, a correta identificação da formação e evolução da emulsão é preponderante para tal tarefa. Sendo assim, uma proposta de procedimento para o controle de projeções, quando esta ainda não está totalmente estabelecida poderia iniciar pela diminuição da vazão de oxigênio, seguido pela suspensão da adição de materiais, principalmente materiais refrigerantes que aportem oxigênio. Neste ponto, poder-seia adicionar fluorita, a fim de diminuir a viscosidade da escória.

No caso da projeção já estabelecida, as medidas de controle parecem ser a redução imediata da vazão de oxigênio, seguido da adição de material para furar a escória e promover a liberação dos gases. A redução da altura de lança deveria ser feita apenas após a redução da vazão de $\mathrm{O}_{2}$ e de forma gradativa.

Os resultados e discussões acima foram condensados em um modelo conceitual para as ocorrências das projeções observadas, ilustrado na Figura 6.

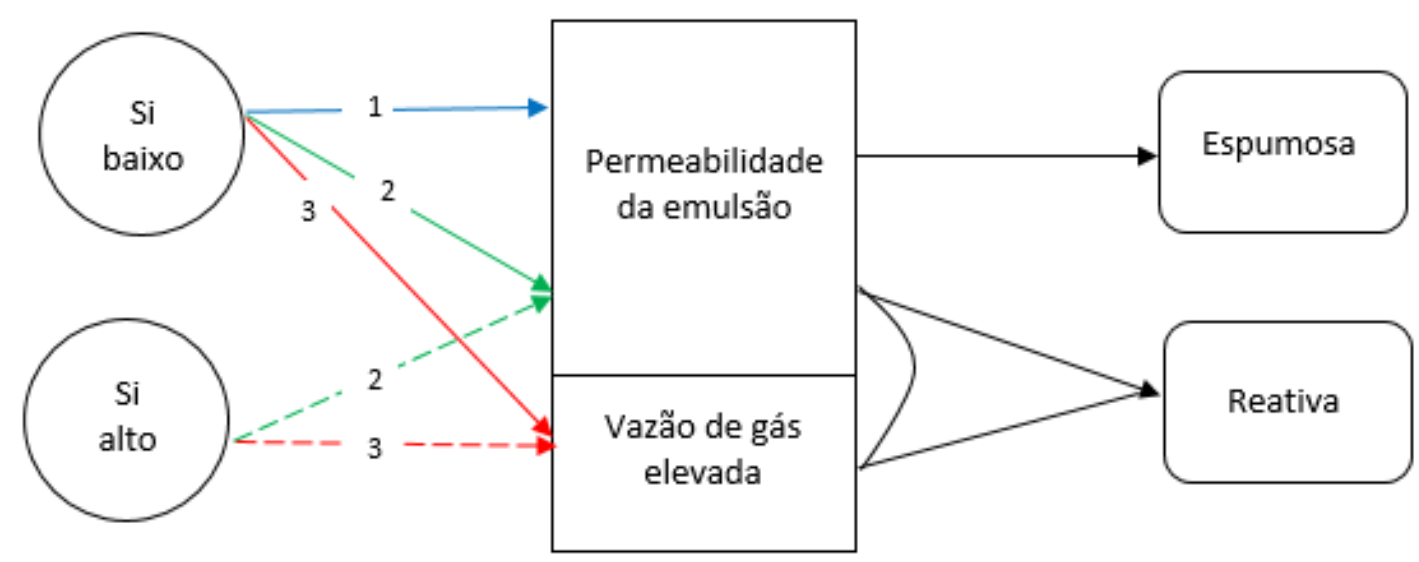

1 - Adição de formadores de escória em um sistema com baixa capacidade térmica.

2 - Redução do $\mathrm{FeO}$ e/ou da basicidade da escória.

3 - Elevado acúmulo de FeO na escória antes da descarburação máxima e/ou adição de minério no início desse período.

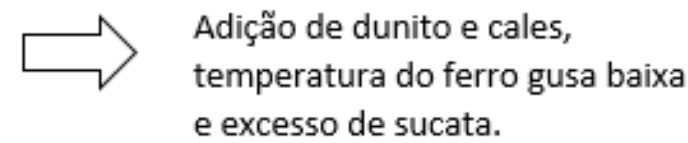

Sopro duro no início e baixa reatividade das cales.

Sopro muito macio no início e uma transição muito forte para sopro duro no início da segunda etapa de descarburação.

Figura 6. Modelo conceitual para projeções observadas na aciaria da ArcelorMittal Tubarão. Fonte: Elab. pelo autor, 2016. 
De acordo com este modelo, para os casos de Si baixo, projeções viscosas seriam decorrentes fundamentalmente dos processos físico-químicos de formação da escória e que define a sua permeabilidade (em princípio, sua viscosidade): temperatura baixa e baixa solubilidade dos fluxantes.

Por outro lado, este modelo preconiza que as projeções reativas seriam oriundas de uma grande geração instantânea de gás. A componente indutora de temperatura baixa não estaria atuando, porém outras também importantes para definição da permeabilidade da escória, como reatividade dos cales e teor de $\mathrm{FeO}$ da escória, seriam também relevantes.

A validação deste modelo de ocorrência da projeção reativa é baseada nas observações das ocorrências de projeções após a medição da sublança intermediária ( $80 \%$ do sopro), comum em situações de reestabelecimento da vazão de oxigênio com o banho contendo teores elevados de carbono. De fato, neste momento do sopro, a escória já estaria bem formada e em elevadas temperaturas, ou seja, com propriedades físicas adequadas, ocorrendo tão somente uma forte e instantânea geração de gás.

\section{CONCLUSÃo}

As projeções ocorreram em ampla faixa de Si do ferro gusa e principalmente em corridas com elevada adição de minério, com maior concentração para teores entre 0,30 e $0,49 \%$ de Si.

Projeções em corridas com baixo teor de Si $(<0,30 \%)$ no ferro gusa ocorreram possivelmente em decorrência de uma baixa permeabilidade dos gases, devido a uma escória de elevada viscosidade gerada em um sistema de baixa carga térmica.

Para gusas de maior teor de $\mathrm{Si}$, onde o volume de escória é elevado, a projeção pode ter ocorrido em decorrência de uma descarburação intensa que teria gerado uma grande quantidade de gás em um instante de tempo curto.

A elevada adição de minério em corridas com elevado aporte térmico teria contribuído significativamente para a ocorrência das projeções em decorrência do seu potencial de resfriamento da escória e da geração de gases.

Amostras de projeção analisadas demonstram a elevada heterogeneidade desta fase.

As medidas de controle devem visar um aumento da permeabilidade da emulsão aos gases da descarburação, assim como a redução da taxa de descarburação, ou seja, da geração de gases.

Para serem eficientes, as medidas de controle devem ser customizadas em função do momento do sopro, uma vez que medidas que seriam eficientes em um momento podem ser desastrosas em outro. 


\section{REFERÊNCIAS}

1 Bramming M. Avoiding Slopping in Top-Blow BOS Vessels [tese de licenciatura]. Lulea: Lulea University of Technology; 2010.

2 Deo B, Overbosh A, Snoeijer B, Das D, Srinivas K. Control of Slag Formation, Foaming, Slopping, and Chaos in BOF. Transactions of the Indian Institute of Metals. 2013, 66(56):543-554.

3 Cicutti C, Valdez M, Pérez T, Donayo R, Petroni J. Analysis of slag foaming during the operation of an industrial converter. Latin American Applied Research. 2001, 32:237240. 